\title{
O objeto objeto na análise organizacional: a teoria ator-rede como método de análise da participação dos não-humanos no processo organizativo
}

\author{
The object object in organizational analysis: actor-network theory as a analytic \\ method about the participation of non-humans in organizing
}

\author{
César Tureta ${ }^{1}$ \\ Rafael Alcadipani ${ }^{2}$
}

\section{Resumo}

O objetivo deste artigo é analisar os objetos e elementos não-humanos como agentes constituintes do processo organizativo, por meio de uma abordagem pós-humanista: a teoria ator-rede. Considerando a crescente influência do pós-humanismo nas ciências humanas e, mais especificamente, na análise organizacional, desenvolvemos a idéia de aplicação do conceito de simetria, da teoria ator-rede, como uma lente de análise que permite investigar, simetricamente, humanos e não-humanos em práticas específicas no âmbito das organizações.

Articulamos a noção de simetria com o desdobrar de práticas sociais, bem como o papel dos objetos e nãohumanos nesse processo. Apresentamos e discutimos, a título de ilustração, alguns trabalhos que identificaram como os elementos materiais se fazem presentes e dão forma d̀s atividades no cotidiano organizacional. Concluímos que a inclusão dos não-humanos na análise das organizações permite ampliar os horizontes de investigação, muito embora, o principal desafio talvez seja construir uma metodologia suficientemente capaz de apreender e observar esses elementos em seus contextos de atuação.

Palavras-chave: estudos organizacionais; teoria ator-rede; práticas sociais.

Abstract

Departing from a post-humanist perspective (Actor-Network Theory), this paper seeks to analyze objects and non-humans as constituent agents of organizing. Given the increasing influence of post-humanist perspectives in social sciences, and more specifically in organizational analyses, we develop the idea about the application of ANT symmetry notion as a key resource to analyze organizational practices. We try to articulate the symmetry notion with considerations about social practices in order to stress the role of objects and non-humans in organizing. Besides that, we present and discuss some empirical studies developed in this direction as well as highlight some empirical investigation possibilities. We conclude that by taken into account the role played by non-humans and objects it is possible to open new insights in the analysis of social practices. We also highlight that the main challenge is to produce a method that can analyze such processes without relying on humans as central actors.

Key words: organizational studies; actor-network theory; social practices.

\footnotetext{
${ }^{1}$ Mestre em Administração de Empresas pelo Programa de Pós-Graduação em Administração da Universidade Federal de Lavras (PPGAD/UFLA) Doutorando em Administração de Empresas pela Escola de Administração de Empresas de São Paulo da Fundação Getúlio Vargas (EAESP/FGV). Professor da Escola Superior de Propaganda e Marketing de São Paulo - ESPM/SP. Endereço: Rua Maracá, n. 132, apto. 124 - Vila Guarani/São Paulo - Brasil - CEP: 04313210. E-mail:cesartureta@gvmail.br

2 Mestre em Administração Escola de Administração de Empresas de São Paulo da Fundação Getúlio Vargas (EAESP/FGV) PhD pela Manchester Business School. Professor da Escola de Administração de Empresas de São Paulo/Fundação Getulio Vargas - EAESP/FGV. Endereço: Alameda Lorena, n. 105, apto. 61 - Jardins - São Paulo/SP - Brasil - CEP: 01424000. E-mail: rafael.alcadipani@fgv.br

Artigo submetido em 10 de janeiro de 2007 e aceito em março de 2008.
} 


\section{Introdução}

Nossas atividades lúdicas, de trabalho, esportivas, ou até mesmo a simples ação de fazer uma refeição, exigem, na maioria das vezes, a participação de elementos materiais. Estes, por sua vez, dão forma e delineiam essas práticas, em maior ou menor intensidade, dependendo da centralidade do objeto para o seu desenvolvimento. Almoçar uma comida tradicional brasileira, usualmente, requer talheres como garfo e faca. Esses objetos são importantes para a dinâmica da prática "comer", pois ela será (pelo menos, em partes) construída por esses elementos. Contudo, ao comer uma comida japonesa utilizando ohashi ${ }^{1}$, provavelmente, a prática de comer sofrerá alterações em função da inserção de elementos diferentes; ou seja, a comida em si e os "talheres" típicos japoneses.

A entrada de novos elementos provoca mudanças na atividade e no processo como ela é realizada (e.g. o movimento das mãos), bem como, pode demandar a inserção de novos elementos (e.g. molho shoyo, em vez de azeite). No contexto organizacional, pouco restará de um gerente se for retirado seu computador, sua agenda, seus sistemas de informação, suas planilhas e relatórios, suas canetas, papéis ou a sua mesa de trabalho. Um atendente de telemarketing não pode ser designado como tal sem linhas telefônicas, manuais de procedimento, computadores e até mesmo sem aquela irritante música que ouvimos a sua espera. A faxineira de uma organização requer, em geral, panos, vassouras e rodos para poder executar suas funções. O que seria de um operário sem máquinas, ferramentas e o conhecimento adquirido pela experiência de lidar com um equipamento por anos?

Dessa forma, é difícil negar que elementos materiais também compõem as práticas que se desenvolvem no contexto das organizações, ora como mediadores das relações, ora como elementos centrais de uma atividade, gerando-a e/ou alterando-a permanentemente. A questão da materialidade no mundo social já era considerada, ao menos, desde Karl Marx (e.x. ao explorar de forma aprofundada a questão da mercadoria no volume 1 de $O$ capital.). A antropologia também aborda esse tema, a ponto de existirem periódicos dedicados ao assunto, principalmente, no que diz respeito à questão da "cultura material" (e.g. Journal of Material Culture, 1996). Todavia, apenas recentemente ocorreram significativas mudanças na direção de incluir - de maneira mais ampla - esses elementos na análise social (ENGESTRÖM; BLACKLER, 2005).

Da mesma forma, o reconhecimento da importância dos elementos não-humanos como agentes constituintes do processo organizativo e sua participação no espaço organizacional ainda são bastante incipientes (ver COOPER; LAW, 1995; ENGESTRÖM; BLACKLER, 2005; HAGEMEIJER, 2004). No Brasil, estudiosos das organizações também já destacaram a importância da materialidade nas relações sociais e organizacionais (e.g. MISOCZKY; AMANTINO-DE-ANDRADE, 2005). Vale mencionar, ainda, que, no contexto organizacional, esses elementos podem ser considerados de várias formas. Eles podem ser explorados como fetiches, artefatos culturais, elementos estéticos, como expressão artística, como mediadores de ações ou, simplesmente, serem ignorados.

Porém, a tendência da área e das ciências humanas é atribuir possibilidade de ação somente para humanos, relegando aos não-humanos um papel secundário. Na verdade, quando objetos são retratados nas análises sociais tradicionais, ou surgem como artefatos culturais ou como fetiches, cuja ação é sempre atrelada única e exclusivamente à interpretação humana (LATOUR, 2005). Pretendemos, portanto, apresentar uma maneira diferente de pensar a questão dos não-humanos, sem, contudo, assumir que tal perspectiva seja a mais "real" ou a mais "verdadeira".

Nesse sentido, este artigo visa analisar e discutir objetos e elementos não-humanos como agentes constituintes do processo organizativo, a partir de uma perspectiva pós-humanista. Argumentaremos que uma maneira de compreender tal processo numa perspectiva pós-humanista (ou pós-social) seria considerar, simetricamente, humanos e não-humanos; isto é, colocá-los em um mesmo plano analítico sem estabelecer qualquer tipo de primazia de um sobre o outro (KNORR-CETINA, 2001; LATOUR, 1994b, 2000, 2001; LATOUR; 
WOOLGAR, 1997; LAW, 2003). Também discutiremos as possíveis contribuições desse tipo de abordagem para a análise das organizações.

Para tanto, iniciamos o artigo tratando da "virada para a prática" nas ciências sociais, que ocasionou um maior interesse pela questão da materialidade na vida cotidiana. Em seguida, abordamos brevemente a perspectiva pós-humanista, que procura reconhecer e retratar a importância dos objetos na vida social. Posteriormente, apresentamos o princípio da simetria, colocando-o como um "instrumento" de análise possível de ser empregado na investigação dos não-humanos no processo organizativo. Na seqüência, discutiremos como tais elementos estão presentes nas práticas desenvolvidas nas organizações e, depois, apresentamos nossas considerações finais.

\section{Por uma análise das práticas sociais}

\section{A virada da prática}

Embora a análise das práticas cotidianas faça parte das ciências sociais - ao menos, desde as pesquisas desenvolvidas por etnometodologistas (e.g. GARFINKEL, 1967; MEHAN; WOOD, 1975) - e seja possível encontrar elementos de uma "teoria da prática social" nos trabalhos de diversos autores (e.g. Pierre Bourdieu, Anthony Giddens, Jean Lave, Etienne Wenger, Michel de Certeau, Hubert Dreyfus, Michel Foucualt, Bruno Latour, John Law e Jean-Françoise Lyotard) ${ }^{2}$, só ultimamente essa perspectiva tem ganho maior proeminência (FOOK, 2002; SCHATZKI; KNORR-CETINA; VON SAVIGNY, 2001). Isso se deve a um crescente interesse em investigar as atividades que constituem as diferentes dimensões da realidade (e.g. SCHATZKI, 2002). Nesse contexto, alguns autores afirmam que houve recentemente uma "mudança para um foco na prática" nas ciências sociais contemporâneas (CONTU; WILLMOTT, 2006; SCHATZKI; KNORR-CETINA; VON SAVIGNY, 2001).

De acordo com Reckwitz (2002), as teorias da prática se apresentam como uma alternativa atrativa para pesquisadores insatisfeitos com a teoria social moderna ${ }^{3}$. Dessa forma, esse tipo de análise está relacionado com um desejo de livrar as atividades cotidianas do determinismo imposto por categorias de análise rígidas como sistema e estrutura social, questionar a ação individual como aquilo que exclusivamente constitui o fenômeno social e tentar ir além das típicas oposições entre ação e estrutura como recurso heurístico (SCHATZKI, 2001a). A abordagem das práticas tem a tendência de considerar que tanto as ações quanto os indivíduos são construídos por meio das práticas e que o social "é um campo de práticas incorporadas $e$ materiais organizado centralmente em torno de um conhecimento prático compartilhado" (SCHATZKI, 2001a, p.3). Vale ressaltar que a teoria da prática não corresponde a uma verdade absoluta sobre os "fatos" sociais, nem pressupõe que outras versões da teoria social sejam falsas (RECKWITZ, 2002). Entretanto, representa um caminho para compreender contextos sociais, privilegiando a análise da (re)construção das relações entre pessoas e entre pessoas e objetos.

A "mudança para a prática" também está influenciando os estudos organizacionais. Até mesmo um seminário internacional sobre o tópico, patrocinado pelo Grupo Europeu de Análise das Organizações (Egos), foi realizado no ano passado. Além disso, há uma crescente literatura sobre o tema presente na análise da estratégia como uma prática (WHITTINGTON, 1996; JARZABKOWSKI, 2005), da tecnologia (e.g. ORLIKOWSKI, 2002), do trabalho (e.g. ORR, 1996), do aprendizado (GHERARDI, 2000), bem como, do marketing e do consumo (WARDE, 1994). Aliás, é possível traçar a origem de análise sobre as práticas organizacionais, de certa forma, nos experimentos de Hawthorne. Porém, de acordo com Barley e Kunda (2001), nos últimos 40 anos há uma tendência, nos estudos organizacionais, de deixar de realizar investigações a respeito de como as atividades são, de fato, desempenhadas nas organizações. Consequentemente, a teoria das organizações contemporânea se fundamenta em teorizações abstratas e na realização de pesquisas quantitativas que acabam por ignorar as práticas cotidianas e impor o que se pretende investigar na realidade. Ademais, as pesquisas qualitativas tendem, hoje, na nossa área, a serem muito mais fundamentadas em entrevistas do que em 
observações diretas de atividades organizacionais (BARLEY; KUNDA, 2001). Dessa forma, o retorno do foco nas práticas pode estar associado a uma preocupação em diminuir o hiato existente entre o que é apresentado pelas teorias sobre o que as pessoas fazem e o que elas fazem de fato (JARZABKOWSKI, 2004; YANOW, 2006).

Seguindo o que destacamos no início desta sessão, os estudos sobre práticas possuem diversas origens teóricoconceituais. Na tentativa de analisar as diferentes contribuições para essa perspectiva, Rache e Chia (2007) apresentam pontos de encontro e dissimilaridades entre alguns autores das perspectivas da prática. A partir de uma matriz contendo em um dos eixos as dimensões "individualismo metodológico" versus "relacionismo" e, no outro, "práticas flexíveis" versus "práticas estáveis", os autores discutem o conceito de práticas sociais com base na contribuição de diversos teóricos. Um resumo desse mapeamento pode ser visto na figura 1. $\mathrm{O}$ individualismo metodológico diz respeito à concepção de ser humano como essencialmente consciente, intencional e motivado no direcionamento de suas ações, orientadas para objetivos específicos. Em contrapartida, o relacionismo rejeita a idéia de que as ações humanas são, necessariamente, governadas pelas intenções individuais dos atores. Essas ações deveriam ser explicadas pela lógica das práticas culturais. Já a visão de práticas estáveis está relacionada com a institucionalização das práticas na vida social, tendendo a persistir no tempo e no espaço, com poucas alterações adaptativas. A visão de práticas flexíveis, por sua vez, remete ao caráter provisório, flexível e adaptativo das mesmas, que estão constantemente se transformando de acordo com o contexto local onde emergem (RACHE; CIA, 2007).

Para Schatzki (2001a), embora a multiplicidade de perspectivas da prática não permita o estabelecimento de uma abordagem unificada sobre o tema, um ponto convergente entre esses teóricos é a idéia de que fenômenos como conhecimento, significados, atividades humanas, ciência e poder são manifestações ou componentes do campo da prática e que, portanto, só podem ser compreendidos e analisados a partir dele. Assim, de modo geral, os estudos da prática pretendem analisá-las tanto em seu campo, quanto em alguns subdomínios, (como por exemplo, a ciência); ou ainda, tratam o campo da prática como o espaço para estudar a natureza e as transformações dos fenômenos (SCHATZKI, 2001a).

No próximo subitem, trataremos de algumas das idéias de um dos principais autores a discutir a questão da prática nos estudos organizacionais e que, como tal, tem influenciado pesquisas nesse campo.

Figura 1 - Matriz das diferentes teorias da prática

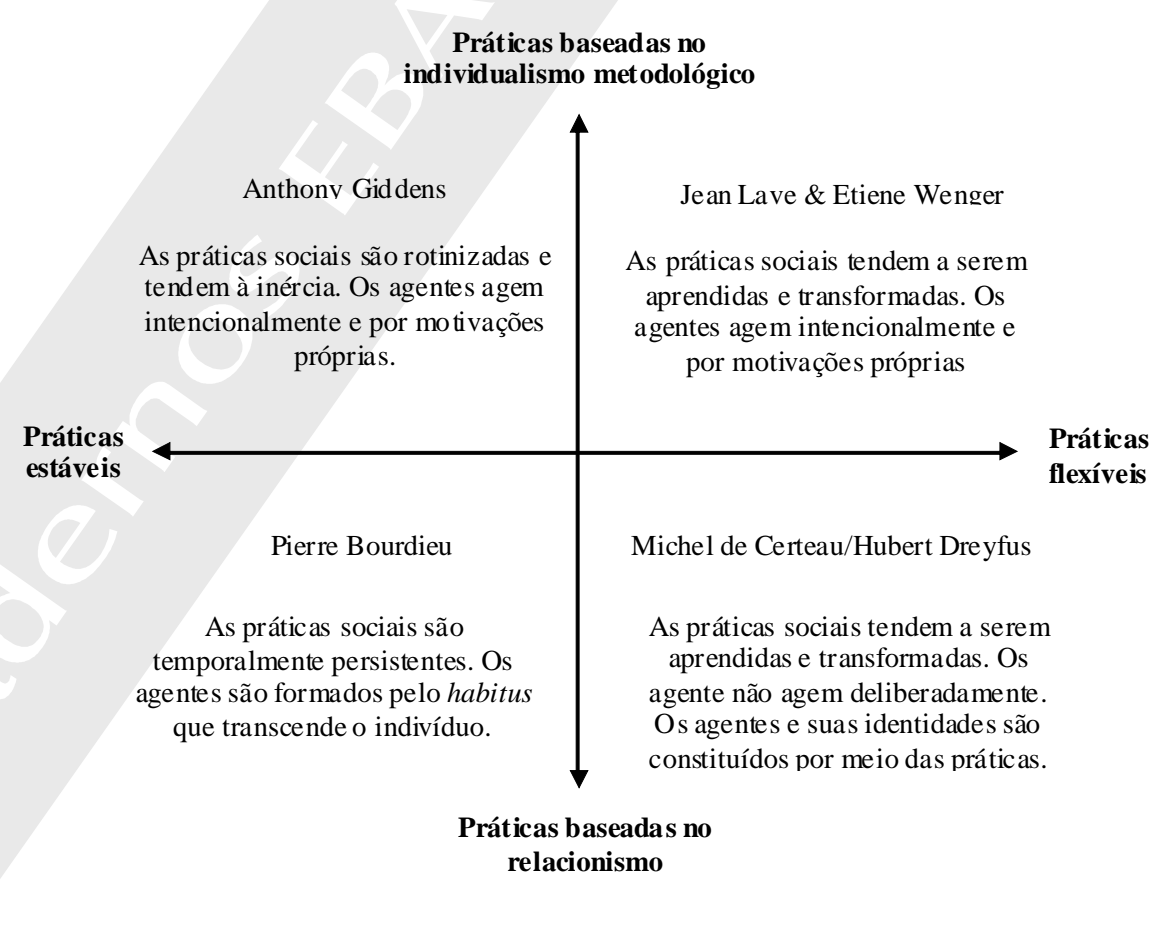


Fonte: Rasche e Chia (2007).

\section{Theodore Schatzki e as "organizações como elas acontecem"}

Schatzki é um dos autores contemporâneos que procuram investigar as interações sociais e as atividades que as envolvem, a partir da relação entre humanos e não-humanos (ver SCHATZKI, 1996, 2002, 2003, 2005; SCHATZKI; KNORR-CETINA; VON SAVIGNY, 2001). Ele ainda tem se destacado com publicações a respeito da questão das práticas nas organizações (SCHATZKI, 2005; 2006; CONTU; WILLMOTT, 2006). Suas idéias sugerem que práticas e ordens sociais são instituídas em (ou constituídas por) fenômenos locais e que, mais do que o estabelecimento de dicotomias entre micro e macro, esses níveis, na verdade, precisam ser compreendidos a partir da inter-relação entre práticas e arranjos (SCHATZKI, 2005). Nesse sentido, o espaço no qual se desdobra qualquer aspecto da vida social é composto por uma malha (conexões) de práticas humanas e arranjos materiais, que estão profundamente interligados, representando o campo/domínio do qual os fenômenos fazem parte (SCHATZKI, 2003, 2005). Por exemplo, no caso de atividades desenvolvidas em um banco, o requerimento de um relatório ou outro procedimento qualquer ocorre como parte intrínseca das práticas bancárias. Assim, uma das tarefas envolvidas na análise dos espaços e de seus eventos é delimitar quais atividades compõem um evento ou fenômeno de interesse e traçar a cadeia de ação dos humanos e nãohumanos que circulam e conectam as redes responsáveis por manter ou transformar o fenômeno social de interesse (SCHATZKI, 2003). Schatzki (2003; 2005) salienta que esses espaços de coexistência humana e material são compostos por três dimensões: a) práticas; b) arranjos materiais; c) arranjos de conexões materiais e arranjos físicos.

Para esse autor, as práticas são constituídas por um pacote de atividades, no qual os participantes operam em uma arena onde determinadas ações e fins são prescritos ou aceitáveis em certas ocasiões, representando um envolvimento temporário de um conjunto de ações e falas ${ }^{4}$ (SCHATZKI, 2002). Assim, um conjunto de práticas inclui uma conexão de atividades organizadas como parte das ações e relações que ocorrem entre as pessoas, como a prática religiosa, política, ou até mesmo a prática de jogar futebol ou cozinhar (SCHATZKI, 1996; 2002; 2003; 2005). A segunda dimensão é representada pelos arranjos materiais, compostos por pessoas, artefatos, organismos e coisas, em que cada um possui significado e identidade. Arranjos materiais são aqueles objetos e pessoas que estão presentes nas práticas sociais. A terceira dimensão compreende arranjos que envolvem conexões materiais, como linhas de comunicação (e.g. telefones), e arranjos físicos. Por exemplo, a coexistência de pessoas (alunos, professores, funcionários etc.) em uma escola ocorre por meio da organização e da configuração dos corredores, das salas de aula, das secretarias, do quadro-negro, bem como das comunicações estabelecidas com outros locais (SCHATZKI, 2003; 2005). Aqui, fica evidente que essa perspectiva assume uma distinção, em princípio, entre humanos e a não-humanos.

As práticas e os arranjos mantêm uma relação muito próxima, pois aquelas são constituídas de várias formas por estes, assim como os arranjos formam o conjunto de práticas e são (re)criados dentro delas (SCHATZKI, 2003; 2005). Schinkel (2004) emprega, inclusive, o termo "objeto-prática" para reforçar a idéia de que objetos e práticas se definem mutuamente. Ao considerar que os fenômenos não são fixos e estáveis, mas são ontologicamente mutáveis, há uma mudança na direção de uma maior ênfase na idéia de fluxo e transformação (SCHATZKI, 2002), conferindo às práticas um caráter mais dinâmico e construtivo, em termos da sua dinâmica relacional (KNORR-CETINA, 2001). Na escola, por exemplo, a malha de práticas (ensino, avaliação) e arranjos (diário do professor) dentro da sala de aula está ligada à malha de práticas (inserção da nota dos alunos no sistema de computador) e arranjos (o próprio sistema) da secretaria da escola. Focar nas práticas em contexto organizacional está intimamente relacionado com estudar as "organizações como elas acontecem" (SCHATZKI, 2006). A idéia de "acontecer" implica que as organizações são constituídas de ações que são desempenhadas (SCHATZKI, 2006) e está fundamentada na visão de que elas são conjuntos de práticas e materiais sociais (SCHATZKI, 2005). Isso implica uma separação, a princípio, entre prática e materialidade; ou, ao menos, que coloca os humanos desempenhando papéis centrais no desempenho das práticas. 
De uma forma geral, práticas são consideradas um "conjunto de atividades humanas centralmente organizadas em torno de uma compreensão prática" (SCHATZKI, 1996, p.89). Porém, tal visão tende a alocá-las como fundamentalmente associadas e dependentes da interpretação humana. De fato, mesmo quando a materialidade presente nas práticas é considerada, como destacado anteriormente, ela tende a ser considerada dependente dos humanos (veja SCHATZKI, 2001a, 2006; ORLIKOWSKI, 2002). É exatamente nesse sentido que Schatzki (2001a, p.2) destaca que para uma minoria de estudos pós-humanistas associados com estudos da ciência e tecnologia (e.g. DREYFUS, 2001; GANE, 2006; HARAWAY, 1991; LAW, 1997c; LATOUR, 2005; PICKERING, 2001), o conjunto de atividades presentes nas práticas também envolve aquelas dos nãohumanos. Para Knorr-Cetina (2001, p.187) um dos principais desafios para o estudo das práticas é "dissociar a noção de práticas de alguma forma de sua fixação nos humanos", algo que está presente na idéia de simetria radical da TAR. Porém, antes de tratar dessa questão, na próxima sessão discutiremos o pós-humanismo.

\section{Pós-humanisno}

O humanismo representa a principal forma de pensar da sociedade moderna ocidental. Suas origens remontam à Europa dos anos 1500 e 1600, período em que o ser humano passou a ser celebrado como criador e pensador onipotente, única fonte de significado, de valores e da verdade. Nesse sentido, o humanismo pode ser definido como "a atitude filosófica que faz do homem o valor supremo, e que vê nele a medida de todas as coisas" (JAPIASSÚ; MARCONDES, 1996, p.132) Os ideais humanistas atravessaram todos esses anos e ainda permanecem vivos no século XXI, permeando diversas esferas intelectuais (SCHATZKI, 2001a).

Uma das principais consequiências do humanismo foi a modernidade. Conforme argumenta Latour (1994a), um dos mecanismos de funcionamento do pensamento moderno é a separação entre objetivo e subjetivo, natural e social como unidades de análise distintas para investigação. Como resultado direto de tais separações, ocorreu o estabelecimento de campos de conhecimento científicos que analisam cada um desses fatores. Assim, as ciências sociais cuidam do "social", enquanto as ciências naturais cuidam da "realidade". Para o autor, essa distinção purifica a complexidade do real. Ademais, ao focar exclusivamente nos humanos, há a tendência de se retirar de cena os materiais que constroem e moldam atividades cotidianas, não permitindo que se contemple um escopo maior de participantes das práticas sociais, atribuindo às pessoas toda a responsabilidade pelas ações, desprezando, assim, o papel dos não-humanos no processo.

Nesse sentido, Pickering (2001) argumenta que precisamos reconhecer a recíproca constituição existente entre materiais e agência humana, o que demanda uma teoria social pós-humanista. O pós-humanismo lança luz na entidade material, descentralizando os humanos do foco da análise e desafiando as suposições humanistas da modernidade. Segundo Gane (2006), embora a origem do pós-humanismo seja alvo de disputas, o movimento promovido pela cibernética na década de 1940 é considerado marcante na história de sua constituição. A difusão, porém, ocorre somente no início da década de 90, com o trabalho de Haraway (1991), no qual a autora discute a idéia de que as fronteiras que separavam os humanos de outras entidades (animais e máquinas) já não são mais sustentáveis, se é que o foram algum dia (GANE, 2006).

O foco fundamental aqui é na idéia de ciborgues. Um ciborgue é um híbrido composto por máquina e organismo, representando uma criatura da realidade social, assim como da ficção (HARAWAY, 1991; PARKER, 1998). Segundo Moser e Law (1999, p.215), um ciborgue é o resultado da interação entre materiais e corpos, que produz algo que vai além de corpos isolados. É "uma unidade, mas também um composto de partes que não podem ser reduzidas umas às outras, que por sua vez são diferentes em espécie, e que não são homogêneas. Mas que também estão internamente relacionadas umas com as outras". No entanto, esse conceito não se resume apenas à associação humano/máquina, mas sim à dependência de uma heterogeneidade material (ver MOSER; LAW, 1999).

De modo geral, o surgimento do interesse pelos objetos e elementos não-humanos ${ }^{5}$ pode ser atribuído a uma série de fatores, mas, principalmente, a três tradições de pesquisas, como destacam Engeström e Blackler (2005): 
a) aos estudos culturais e antropológicos, que demonstraram uma completa indissociabilidade entre o social e o material;

b) aos estudos feministas, bem como aos estudos sociais da ciência e tecnologia, que trabalham tanto com a idéia do caráter híbrido entre coisas e pessoas, quanto da simetria entre humanos e nãohumanos;

c) aos estudos calcados nas "teorias da prática", que estabelecem fronteiras com as duas tradições anteriores (ENGESTRÖM; BLACKLER, 2005).

O surgimento e, principalmente, o fortalecimento dessas abordagens nas ciências sociais possibilitou aos teóricos repensarem o conceito de "social", até então resumido às relações e interações humanas. O reconhecimento da materialidade do social amplia o número de elementos em análise, permitindo entender que as ações dos atores estão dispersas nas relações humanos/não-humanos, e não somente concentradas nos primeiros (veja LAW; URRY, 2004). A adequação a essa nova forma de pensar demanda uma reformulação da noção de ontologia do social (LATOUR, 2005), passando a incluir perspectivas de uma ontologia do existindocom-objetos (SCHINKEL, 2004). Para Latour (2005), deveríamos centrar nossa atenção no processo de ordenação social como resultado da associação entre humanos e não-humanos, sem nos limitarmos aos aspectos puramente sociais, configurados pelas entidades humanas, pois, como destacam Law e Urry (2004), a realidade representa um efeito relacional; ela é produzida e se estabiliza por meio de interações que são, concomitantemente, materiais e sociais.

Pensar dessa forma significa pensar em um desenvolvimento pós-social ou "sociabilidade centrada no objeto" (KNORR-CETINA, 1997b). Significa considerar que os objetos são elementos indispensáveis para qualquer prática, pois a sua realização, freqüentemente, demanda a utilização de determinados tipos desses materiais. Jogar futebol pressupõe, minimamente, a existência e a participação de uma bola, além das traves que formam o gol, para o seu desenrolar. Enviar uma mensagem eletrônica no trabalho pressupõe uma série de elementos materiais, sem os quais essa prática seria impossível. Assim, a centralidade de alguns objetos, ou elementos não-humanos, na prática é tão importante, que sua ausência pode suspender e até inviabilizar a realização da atividade. Quando a bola sai de campo, o jogo é temporariamente interrompido até que ela seja reposta. Quem nunca se irritou com a perda de conexão na rede mundial de computadores ou com a "queda" da rede eletrônica da universidade?

Além disso, é comum considerar que há distinção clara entre sujeitos e objetos. Porém, uma breve visita a uma unidade de terapia intensiva neonatal mostra uma realidade bastante diferente (BROWN; MIDDLETON, 2005). A sobrevivência do recém-nascido prematuro depende de um complexo arranjo material, que se adapta e muda constantemente, dependendo das circunstâncias específicas. A fronteira entre o humano e o material é constantemente redefinida, na medida em que o bebê necessita de respiração assistida, de monitoramente cardíaco, de vitaminas e medicamentos específicos etc. (veja BROWN; MIDDLETON, 2005). Essa constante redefinição igualmente ocorre quando, por exemplo, alguém necessita de uma cadeira de rodas com mecanismos de controle remoto acoplados para que consiga executar atividades rotineiras, como abrir e fechar uma porta ou enviar um e-mail (veja MOSER; LAW, 1999).

Dessa maneira, as perspectivas pós-humanistas reconhecem que tanto humanos quanto não-humanos se constituem como tais a partir das práticas que desempenham. (veja HARAWAY, 1991; LATOUR, 2005). A relação sujeito/sujeito, comum à teoria clássica da sociologia, perde prioridade e cede lugar à relação sujeito/objeto (RECKWITZ, 2002). Apesar dos objetos se apresentarem para nós de maneira objetiva, para entendê-los, não podemos separá-los dos arranjos que materializam na prática (SUCHMAN, 2005) e que os constroem (LATOUR, 1999; MOL, 2002). Isto é, esses elementos são processos em constante definição, adquirindo permanentemente novas propriedades e transformando as anteriores (KNORR-CETINA, 1997b, 2001). Isso significa dizer que eles são precários; que ganham atributos e características, não por causa de uma essência existente a priori, mas, sim, devido às associações que formam com outros objetos e pessoas nas atividades em que estão engajados, podendo, ainda, adquirir propriedades humanas (veja CONTU; 
WILLMOTT, 2006; LATOUR, 1999; MOL, 2002). Esse tipo de análise pressupõe tratar simetricamente humanos e não-humanos, como discutiremos na próxima sessão.

\section{Investigando simetricamente humanos e não-humanos: a contribuição da teoria ator- rede (TAR)}

\section{A TAR}

Estudar os objetos e elementos não-humanos representa um desafio, no sentido de encontrarmos uma maneira de analisá-los, de forma que não sejam vistos apenas como artefatos simbólicos que compõem o espaço organizacional, mas, sobretudo, como agentes ativos no processo organizativo. Nesse sentido, a TAR representa um caminho para suprimir as divisões essencialistas e posições fixas, tal como humano/não-humano.

A origem da TAR $^{6}$ está vinculada aos trabalhos de Michel Serres, Algirdas Greimas, Isabel Stengers, Gabriel Tarde e Harold Garfinkel (veja LATOUR, 2005; McLEAN; QUATTRONE, 2006). Seu desenvolvimento inicial se realizou nos estudos da ciência e tecnologia (e.g. EDGE, 1994; BUTTON, 1993; GRINT; WOOLGAR, 1997; MACKENZIE; WACJMAN, 1999; PINCH; BIJKER, 1984, 1987; WILLIAMS; EDGE, 1996), tendo como principais autores Bruno Latour, Michel Callon e John Law. Originalmente, essa perspectiva se concretizou como uma alternativa às abordagens que privilegiavam somente o papel desempenhado isoladamente pelos humanos (e.g. BIJKER, 1995; GRINT; WOOLGAR, 1997; PINCH; BIJKER, 1984; 1987;) ou pelos artefatos (WILLIAMS; EDGE, 1996) na compreensão do desenvolvimento e das mudanças tecnológicas.

A teoria ator-rede é uma perspectiva de análise que não parte de suposições previamente definidas sobre os fatores social, econômico e técnico. Um de seus pressupostos fundamentais é o de que não há qualquer tipo de definição rígida que possa ser aplicada em todas as situações. Nesse sentido, Callon (1986) argumenta que a TAR tenta abandonar os conceitos tradicionais da sociologia, os quais são fundamentados em categorias sociais preestabelecidas e na rigorosa divisão entre social e natural.

Na TAR, as entidades são analisadas sem qualquer suposição sobre o que e/ou quem são (BUTTON, 1993). Isso não significa negar a existência de divisões, mas entender que as mesmas são efeitos ou resultados e, não, algo estabelecido a priori (LAW, 1997a, 1997b, 1999a). Essa abordagem compreende uma aplicação da semiótica, uma vez que parte da idéia de que as entidades são constituídas e adquirem seus atributos por meio do conjunto de relações que estabelecem com outras entidades. Pelo menos, a princípio, tudo pode ser considerado incerto e reversível (LAW, 1997a, 1999a).

A rede de atores, como argumenta Law (1992), é um processo no qual porções e peças do social, do técnico, do conceitual e do textual são postos juntos e, então, convertidos em um conjunto de materialidades heterogêneas, o que permite que o mundo seja organizado de diferentes maneiras, conferindo à TAR um caráter ontologicamente relativista (LEE; HASSARD, 1999). Esse caráter relativista pressupõe que não devemos assumir como certo a existência de um sistema macrossocial, de um lado, e, de outro, porções e peças derivadas da dimensão microssocial (LAW, 1992). Para essa abordagem, interessa entender como as entidades são construídas por meio de processos múltiplos e materialmente heterogêneos (LATOUR, 2005).

Assim, vivemos em um mundo em que as relações sociais estão imersas em uma variedade de materiais. Portanto, a separação entre objetos e fatores sociais demonstra ser um grande equívoco (LAW, 1986), já que na ausência dos não-humanos, as nossas interações ficariam limitadas em termos do que poderíamos fazer com nossas habilidades (LATOUR, 1994b). Dessa forma, a TAR não representa uma simples reflexão sobre o social, mas, sim, sobre associações que propiciam conexões e relações com elementos não-sociais (LATOUR, 2003), permitindo analisar casos nos quais a separação entre humanos e não-humanos ${ }^{7}$ não é clara e os atores possuem variadas formas (CALLON, 1999). É nesse contexto que podemos pensar o princípio da simetria radical. 


\section{Princípio da simetria radical}

O princípio da simetria foi formulado inicialmente por Bloor (1976), contribuindo para o início dos estudos da sociologia do conhecimento científico na Grã-Bretanha, em meados dos anos 1970 (KNORR-CETINA, 1997a). De acordo com Law (1994), esse conceito contrapunha-se à idéia de que somente os conhecimentos científicos falsos seriam elegíeis para explicações sociológicas. A perspectiva tradicional assumia que a verdade dos fatos científicos referia-se ao resultado de procedimentos metodológicos apropriados, enquanto o conhecimento científico falso ocorria devido à distorção das questões sociais. Ao contrário dessa visão, Bloor (1976) argumentava que ambos, conhecimentos falsos e verdadeiros, poderiam ser sociologicamente analisados nos mesmos termos, visto que são produtos sociais gerados por fatores similares. No entanto, segundo Latour e Woolgar (1997, p. 24), simetria implica para a TAR algo mais do que para Bloor: "cumpre não somente tratar nos mesmos termos os vencedores e os vencidos da história das ciências, mas também tratar igualmente e nos mesmos termos natureza e sociedade"; isto é, não-humanos e humanos. Com isso, a TAR desafiou o emprego de diferentes vocabulários e explicações para explorar a criação social e técnica dos fenômenos (CALLON, 1986), desenvolvendo seu próprio entendimento desse princípio para acessar as redes heterogêneas.

Dessa forma, a noção de simetria, da teoria ator-rede, possibilita-nos analisar os elementos materiais a partir do mesmo plano analítico com que tratamos os humanos, visto que, conjuntamente, são capazes de moldar o contexto em que estão ou são inseridos. Numa instância analítica, não deveríamos considerar os humanos em uma posição privilegiada, dado que humanos e não-humanos são partes da mesma rede que compõe os fenômenos.

Ao entrarem numa dada relação, esses elementos, reunidos, podem auxiliar no desenvolvimento das ações ${ }^{8}$. Em outras palavras, as ações são o resultado da associação entre humanos e não-humanos (LATOUR, 1999; 2005; LAW, 2004).

Conforme já destacado anteriormente, atos geralmente assumidos como normais, tais como comer ou enviar uma mensagem eletrônica, são o produto de um complexo arranjo material composto pela articulação de humanos e não humanos... Dentro desse contexto, o princípio da simetria descentraliza o social como lócus privilegiado da análise (BLOOMFIELD; VURDUBAKIS, 1999); ou seja, o enfoque simétrico significa "não impor a priori qualquer assimetria falaz entre a ação intencional humana e um mundo material de relações causais" (LATOUR, 2005, p.76).

Partindo dessa noção de simetria para análise da realidade, Law (2003) levanta o seguinte questionamento: "nossas explicações sobre as ações dos humanos deveriam ser fundamentalmente diferentes daquelas ações dos não-humanos?" (Ibidem, p.2). A resposta a partir da TAR é, definitivamente, não. Assim, Law (1994, p.12) afirma que:

O princípio da simetria sugere que não haja privilégios - tudo pode ser analisado, e pode (ou deveria) ser analisado nos mesmos termos. Esse princípio elimina as distinções que são tidas como dadas na ordem das coisas e questiona como essas coisas se transformaram no que são.

Latour (2001) argumenta, então, que os materialistas e sociólogos cometem um equívoco ao partirem das essências, ou dos sujeitos ou dos objetos. O que precisamos fazer é começar a atribuir o resultado das ações a um número maior de agentes ou atuantes ${ }^{9}$ do que seria pensado pelos materialistas ou sociólogos. É essa dicotomia entre sujeito e objeto que dificulta entendermos os coletivos ${ }^{10}$ (LATOUR, 2001), uma vez que os híbridos são quase tudo (LATOUR, 1994a). A separação entre humanos e não-humanos limita consideravelmente nossa maneira de analisar e compreender as redes de relações que se estabelecem para a constituição de práticas sociais, já que estas não podem ser entendidas apenas como conseqüência das ações de um desses elementos.

Assim, uma vez que não-humanos são parte de nossa vida cotidiana - e que só se pode falar de atores dentro de redes heterogêneas compostas por humanos e não-humanos -, torna-se impossível estudar as relações sociais e 
técnicas (bem como os resultados das ações) sem considerá-los. De acordo com Callon (1999), a TAR não se baseia em uma teoria estável do ator, pois este é visto como uma entidade sem uma definição muito precisa, cujas motivações para as ações não são, essencialmente, predeterminadas. Ademais, segundo Latour (2001), a ações consistem em uma das propriedades das entidades associadas. Por isso, atribuir a um ator o papel primeiro da ação não significa, necessariamente, anular a composição de forças para explicar uma dada ação. Por exemplo, o ato de voar é uma propriedade da associação de uma série de entidades, entre as quais podemos considerar os aeroportos, os aviões, as pistas de decolagem e aterrissagem e os balcões de venda de passagens (LATOUR, 2001). Entre essas entidades, podemos considerar ainda o piloto, o co-piloto, as comissárias de bordo, os funcionários das companhias aéreas responsáveis pelos check-in e os controladores de vôo, entre outros. A ação, portanto, não ocorre de maneira individual, mas mobiliza entidades humanas e não-humanas com participação ativa no processo (CALLON; MUNIESA, 2005). Quando esses diferentes elementos não estão articulados de forma coerente, ou desarticulam-se mesmo que momentaneamente, fatalidades acontecem, como insistentemente temos visto em nosso país.

Assumir essa concepção de que as ações e as práticas sociais são construídas por pessoas e objetos requer "instrumentos" analíticos capazes de dar conta de fenômenos tão complexos. É nesse sentido que advogamos a favor do uso do princípio da simetria como um meio de analisar situações, onde enfocar apenas os humanos poderia representar uma simplificação do fenômeno. Todavia, a maior dificuldade no entendimento desse princípio é que ele elimina as fronteiras que antes demarcavam a distinção entre humanos e não-humanos, passando a entendê-los como elementos de uma mesma rede de atores e, não, pólos antagônicos e incompatíveis que só podem ser apreendidos separadamente. Isso, de fato, tem gerado uma série de críticas em relação tanto à posição ontológica da análise simétrica, quanto à idéia de ação e aos aspectos morais e éticos de tal abordagem.

\section{Críticas e posicionamentos divergentes}

A noção de simetria da TAR e a idéia de que os objetos desempenham um papel importante no mundo social têm gerado críticas e questionamentos. Por exemplo, Kirsch e Mitchell (2004) argumentam que humanos e não-humanos são provenientes de domínios ontológicos diferentes, além de possuírem diferentes poderes de ação. Vandenberghe (2002) fundamenta sua crítica de maneira similar, sustentando que, pelo fato de humanos e não-humanos pertencerem a dimensões ontológicas distintas, não podem ser analisados simetricamente. Nessa mesma direção, Castree (2002) salienta que a noção de simetria acaba por retratar elementos díspares de forma semelhante, ocultando suas diferenças. Collins e Yearley (1992) argumentam que esse princípio é muito mais uma criação do analista do que algo que possa existir na realidade. Uma vez que o analista está no controle todo o tempo, ele seria capaz de impor a noção de simetria no mundo, sem que ela, de fato, exista.

Tais questionamentos levam à pressuposição de que humanos e não-humanos são constituídos por limites muito bem demarcados e que há uma separação, a priori, de ordem ontológica entre esses elementos. Além disso, embora sem desconsiderar a interconexão entre humanos e não-humanos, alguns autores defendem que somente os humanos são capazes de agir, uma vez que as pessoas é que são responsáveis por conferir significado, valor e uso aos não-humanos (e.g. VANDENBERGHE, 2002).

Não privilegiar os humanos em relação aos não-humanos, analisando-os simetricamente, levantou questionamentos a respeito de uma suposta ausência de moralidade e de humanidade nas abordagens que assumem essa posição (LATOUR, 1999). Fuller (2000) afirma que abordagens que adotam tal perspectiva possuem afinidades com algumas das idéias do capitalismo, na medida em que não é feita qualquer distinção ontológica entre humanos e máquinas. Nesse caso, o autor sugere que a idéia de considerar humanos e nãohumanos simetricamente legitima o tratamento dos primeiros como meros "dentes de engrenagem na roda de uma máquina"; isto é, desumanizando-os e conferindo um caráter depreciativo à agência humana.

Law (1992) contra-argumenta esse tipo de posição, defendendo que dizer que não há uma diferença fundamental entre pessoas e objetos é apenas uma instância analítica e não uma posição ética, em que as 
pessoas são tratadas como máquinas, ou que devemos negar seus direitos, deveres e responsabilidades. O princípio da simetria não tem por objetivo atribuir subjetividade para não-humanos ou considerar humanos como objetos, mas, sim, evitar a distinção sujeito/objeto na análise da construção de processos de ordenamento, que envolve, necessariamente, a relação entre humanos e não-humanos (LATOUR, 2001, 2005).

Além disso, embora tais críticas sejam fundamentais, elas geralmente partem de um pressuposto realista quando apontam a existência de uma distinção real e empírica, a princípio, entre humanos e não-humanos. Trata-se, assim, de colocar a realidade como parâmetro fundamental da validade do argumento e como mais importante do que os pressupostos epistemológicos. Porém, as ciências sociais possuem diversas abordagens igualmente válidas, como há muito nos mostraram Burrell e Morgan (1979). Hoje, sua diversidade vai muito além de tais paradigmas. Para Law (2004), Latour (1999; 2005) e Mol (2002), realidades e objetos não existem dissociados de suas práticas, pois quando investigamos um fenômeno, estamos, ao mesmo tempo, construindo esse fenômeno. Nessa perspectiva, não há certo e errado, verdadeiro ou falso que possa ser comprovado pela observação da realidade. Conseqüentemente, a forma como não-humanos são considerados depende dos fundamentos epistemológico e ontológico seguidos. Diferentes epistemologias não só tratarão do mesmo assunto de maneira diferente, mas também auxiliarão na construção de realidades diferentes.

Com base em toda a discussão da noção de simetria, podemos visualizar o processo organizativo como a reunião ou associação de diversos elementos (gerentes, funcionários, secretárias, mesa, computador, telefone) que, conjuntamente, constituem e respondem pelas ações e atividades cotidianas das organizações (cf. COOPER; LAW, 1995). Dessa forma, a seguir, discutiremos os desdobramentos desse tipo de perspectiva para a análise das organizações.

\section{As organizações vistas pela lente pós-humanista}

\section{Novos direcionamentos}

A importância dos não-humanos para a análise organizacional pode ser constatada na crescente publicação de artigos que tratam da temática "objetos" (veja ADLER, 2005; BROWN, 2004; BRUNI, 2005; CARR; DOWNS, 2004; ENGESTRÖM; BLACKLER, 2005; HAGEMEIJER, 2004; KUHN, 2005; LAW; SINGLETON, 2005; LETICHE; HAGEMEIJER, 2004; LOWE, 2004; MIETTINEN; VIRKKUNEN, 2005; SCHINKEL, 2004; SUCHMAN, 2005). Embora em tais artigos haja uma multiplicidade de abordagens epistemológicas a partir das quais tal enfoque é desenvolvido, destacamos a utilização da teoria ator-rede (TAR). Isto é, há um crescente uso da TAR como lente de análise para fenômenos organizacionais diversos. Ademais, essa abordagem oferece a possibilidade de abordarmos a organização como um processo inacabado, em constante estado de transformação.

Nesse sentido, a relação entre os elementos responsáveis pelo processo organizativo e as práticas geradas recebe maior enfoque, ao se buscar entender, ainda, a possibilidade de humanos serem dotados de propriedades em função da interação com não-humanos e/ou com outros humanos. Por exemplo, um gerente é o efeito de sua rede de relações com subordinados, secretária, computador, relatórios, mesa, telefone etc. Esses materiais contribuem para que ele se torne uma figura poderosa dentro da organização, pois seu poder está distribuído por esses arranjos, somente podendo ser desempenhado valendo-se deles. Portanto, o gerente não é nada mais do que o efeito de uma rede de relações heterogêneas produzidas na organização (LAW, 1997c; LAW; MOSER, 1999) e fora dela.

Letiche e Hagemeijer (2004) salientam que as organizações lançam mão de uma série de arranjos materiais (pessoas e objetos) a fim conquistarem a estabilidade da rede de atores, que é fundamentalmente dependente para a manutenção dessa estabilidade - do relacionamento existente entre os elementos dos arranjos (LETICHE; HAGEMEIJER, 2004). Assim, a inclusão dos objetos e dos não-humanos na análise organizacional representa uma maneira de começarmos a tentar identificar como esses elementos compõem as ações de outras entidades. Dito de outra forma, compreender como a composição de ações específicas está 
distribuída dentro da organização e, por conseqüência, como isso configura o processo organizativo e as práticas organizacionais. A despeito do crescente número de estudos que consideram os não-humanos no processo organizativo, Engeström e Blackler (2005) destacam que há, ainda, poucos insights sobre como as transformações dos objetos podem ser analisadas nos estudos organizacionais.

Após explicitar os novos direcionamentos na análise organizacional que levam em consideração a questão dos objetos, na próxima subseção discutiremos alguns trabalhos empíricos que abordaram os não-humanos nas organizações e sinalizaremos algumas possíveis linhas de investigações futuras.

\section{Não-humanos no processo organizativo}

A análise dos não-humanos no processo organizativo contribui substancialmente para chamar atenção sobre alguns aspectos ignorados pelas abordagens que consideram o "social" apenas uma dimensão formada e/ou transformada pelos humanos. Não obstante a incipiência do desenvolvimento de estudos no campo das organizações sobre a participação de objetos e de não-humanos nas práticas organizacionais, algumas pesquisas empíricas já se propuseram a abordar a temática.

Baseado na idéia de que os humanos e os não-humanos estão ativamente envolvidos na construção da realidade, Bruni (2005) analisa o impacto da adoção de um sistema de registro clínico digital em uma organização hospitalar italiana. $\mathrm{O}$ autor procura verificar como esse objeto - na relação com enfermeiras, médicos e outros objetos - altera a trajetória das ações e práticas no cotidiano daquela organização. Ao observar a rotina de atividades na recepção dos pacientes, Bruni identificou uma série de materiais (resultados de testes, papéis, folhas coloridas, post-it, computadores etc.) essenciais para a identificação do paciente e para a ordenação do relacionamento com as enfermeiras. As situações de trabalho observadas pelo autor, no hospital, demonstraram que o sistema é considerado "um importante agente na organização do dia-a-dia do trabalho, a ponto de que qualquer falha no seu funcionamento redirecionará as trajetórias usuais de ação" (BRUNI, 2005, p.370).

Suchman (2005) investigou o caso da inserção de um novo produto (copiadora) na empresa Xerox como forma de responder a algumas mudanças ocorridas e assegurar seu nicho de mercado, então, sob ameaça dos concorrentes. Essa autora parte da idéia de visualizar a tecnologia como uma prática, que só pode ser acessada na relação com o espaço em que é produzida (SUCHMAN et al, 1999).

Contu e Willmott (2006), tomando como ponto de partida a obra de Orr, Talking about machine, analisam o trabalho de alguns técnicos e a relação deles com as máquinas copiadoras da Xerox, demonstrando a influência de suas práticas na constituição de suas identidades. Os autores discutem que as máquinas copiadoras se transformam em objetos de fascinação, com os quais os técnicos mantêm uma relação fantasiosa de heroísmo, numa batalha pelo controle do bom funcionamento das mesmas. Quando falam sobre seu trabalho, os técnicos atribuem um status de mistério por trás das máquinas, de tal maneira que elas adquirem características que as transformam em algo além de uma simples máquina.

No Brasil, uma linha de investigação interessante seria analisar empiricamente como arranjos materiais e seus elementos constituintes são utilizados pela gestão para vigilância e controle de funcionários nas organizações. Embora alguns trabalhos já tenham sido desenvolvidos nessa direção (e.g. ALCADIPANI; ALMEIDA, 2000; PAÇO-CUNHA et al, 2006), o tratamento simétrico entre objetos e pessoas permitiria enfocar o papel dos nãohumanos nesse processo. Em pesquisa realizada numa organização de tecnologia no formato call center, PaçoCunha et al (2006) identificaram que a configuração do espaço, a disposição de materiais (computador, cadeira, equipamento telefônico, câmeras de vídeo etc.) e os sistemas de informação são utilizados para vigilância e controle dos funcionários, assim como dão forma às práticas e às atividades naquele contexto. $\mathrm{O}$ acondicionamento desses objetos e sua relação com os atores humanos desenham boa parte das práticas e das atividades cotidianas da organização, seja no cumprimento restrito da rotina de trabalho, seja na possibilidade de reduzir sua intensidade por meio de "táticas" utilizadas pelos funcionários para driblarem o monitoramento permanente. 
Em outras situações, os arranjos materiais podem ser usados, ainda, como instrumentos de modificação (positiva) da percepção dos funcionários de uma dada realidade organizacional, embora, nem sempre tais arranjos se estabilizem como associações bem-sucedidas, como demonstram Alcadipani e Almeida (2000). Em sua análise do escritório aberto de uma organização, os autores verificaram que diversos elementos nãohumanos (computadores, mesas e armários novos, divisórias, cafeteira, painéis fotográficos etc.) são capazes de transformar a percepção dos funcionários em relação às tarefas do trabalho. Porém, a mudança de percepção (positiva) se deu apenas temporariamente, na medida em que a nova dinâmica de convivência fez emergir problemas no ambiente de trabalho.

Podemos dizer que os arranjos materiais que, a princípio, teriam um determinado significado, quando entram na relação com outros elementos (no caso, os humanos), ganham novas propriedades e significados, que podem ser completamente opostos daquilo pretendido pela gerência, tornando negativa a percepção que era positiva, como no caso analisado. No entanto, a análise dos autores assume a idéia de percepção como exclusivamente centrada na subjetividade humana, não como algo construído dentro das redes de relações. Nesse sentido, há a possibilidade de se explorar como coisas geralmente atribuídas à subjetividade são constituídas em redes de relações complexas das quais humanos e não-humanos fazem parte.

Outra linha de pesquisa poderia enfocar no questionamento de como a ausência de alguns elementos nãohumanos ou o seu funcionamento precário podem comprometer o desempenho das atividades que deles dependem. Investigações poderiam ser conduzidas, por exemplo, no intuito de analisar como as falhas dos sistemas e a quebra ou as deficiências de equipamentos contribuíram, entre outros fatores, para o recente "apagão aéreo" no nosso país, que desencadeou uma série de mudanças na prática de controle do espaço aéreo.

A responsabilidade pelo caos aéreo foi atribuída, principalmente, aos controladores de vôos. Uma análise mais profunda poderia identificar, por exemplo, que esse caos é resultado ou efeito de arranjos materiais (como equipamentos obsoletos, sistemas de controle defasados e falha de comunicação) e de práticas (o controle do espaço aéreo nas chamadas "zonas cegas"). Assim, a responsabilidade seria atribuída a uma série de atuantes, não se limitando a um ou a alguns atores isolados. Dessa forma, seria possível investigar como não existe uma única e exclusiva responsabilidade, mas, sim, como responsabilidades são atribuídas conforme as redes de relações analisadas. Por exemplo, Law (2004) analisou como investigações sobre um acidente de trens na Inglaterra construíram diferentes responsabilidades, dependendo de quais redes de relações eram traçadas.

Há, ainda, a possibilidade de se tentar compreender como arranjos materiais específicos podem auxiliar a criar inclusões e exclusões específicas. Por exemplo, o sistema de avaliação de cursos de pós-graduação desenvolvido pela Capes experimentou de forma piloto a utilização de um programa de computadores para analisar o desempenho de cursos de pós-graduação em algumas áreas de conhecimento. Tal sistema tende a analisar os indicadores de produção de programas de pós-graduação e atribuir uma nota. Quando esse programa foi adotado de forma experimental em algumas áreas de conhecimento, no último ciclo de avaliações (20042006), as notas de muitos programas foram inferiores àquelas dadas pelas comissões. Isto é, o programa tem o potencial de criar inclusões e exclusões de cursos de pós-graduação em relação a conceitos específicos, diferentes daquelas criadas por comissões de avaliação. Outra possibilidade seria focar o sistema de classificação de periódicos da mesma agência de fomento (Qualis). Tal sistema lista e cria distinções em termos de periódicos acadêmicos e, consequentemente, de publicações que medem o desempenho de profissionais. Ele exerce o papel fundamental de construir, por exemplo, a superioridade de periódicos de língua inglesa (ainda que publicados no Brasil) diante dos periódicos em outros idiomas (para uma critica veja - AMANTINO-DEANDRADE, 2007.). Evidentemente que se pode argumentar que o sistema Qualis, em si, é produzido de forma múltipla e que comissões específicas atribuem as notas dos periódicos. Porém, é difícil negar que a materialização desse sistema, na forma de uma página na rede mundial de computadores, exerce um papel fundamental no ordenamento de outras ações. São exemplos disso, o fato de pessoas enviarem artigos para determinados periódicos e não para outros, o auxílio na construção da ciência anglo-saxã como superior à nacional, a comparação entre periódicos nacionais e internacionais sem que sejam levadas em conta questões de espaço e tempo etc. 
Considerando toda essa discussão, podemos dizer que retirar as pessoas de seu ambiente de trabalho e de suas tarefas é decretar o fim de uma organização, pois não poderíamos imaginá-la funcionando por conta própria. Igualmente, pensá-la sem sua estrutura física, sua rede de computadores, mesas, post-its, relatórios financeiros e banco de dados é imaginar algo completamente irreal. Das organizações mais simples, como um pequeno camelô numa avenida de São Paulo, até aquelas mais complexas, como as organizações virtuais (geralmente, sem localização geográfica claramente definida), todas são compostas e atuam a partir da relação entre humanos e não-humanos. A primeira se organiza por meio da barraca montada na calçada e do apito do seu dono para atrair os clientes; a segunda, da rede mundial de Internet e dos seus experts em sistemas de informação. Dessa forma, não seria possível definir uma organização como uma entidade composta apenas por humanos, nem caracterizá-la somente como um conjunto de peças e porções materiais. Mais do que isso, ela é um híbrido, um ciborgue, pois sua existência, suas "ações", sua imagem e sua relação com o mercado ou com outras organizações resultam de interações entre humanos e não-humanos.

\section{Considerações finais}

Este artigo procurou analisar e discutir objetos e elementos não-humanos como agentes constituintes do processo organizativo, a partir de uma perspectiva pós-humanista. A discussão aqui levantada reflete a tendência, cada vez mais acentuada, de se adotar perspectivas de análise pós-humanistas que vêm ganhando espaço em diversas áreas do conhecimento; especificamente, nos estudos organizacionais. Vale lembrar que esse esforço não é um empreendimento no sentido de deslocar a agência humana para uma posição marginal ou periférica, muito menos reduzi-la ao status de objeto. Pretendemos, apenas, mostrar que a demarcação das fronteiras entre humanos e não-humanos, como dimensões ou "categorias" analíticas diametralmente opostas, já não nos parecem tão claras e fáceis de serem percebidas quando lidamos com o processo organizativo. Compreender o espaço organizacional, considerando sua composição permeada por práticas e arranjos, requer, além de lançar o olhar para as pessoas, reconhecer e atribuir importância aos materiais que coexistem com os atores humanos.

Assim, procuramos destacar abordagens que tratam analiticamente a participação dos elementos materiais na configuração do processo organizativo, traçando a noção de simetria da TAR como um meio de investigação capaz de dar conta dos fenômenos organizacionais, nos quais a existência dos humanos e não-humanos não pode ser facilmente separada. A lente pós-humanista propiciou esse esforço, dado que contribui para desmistificar a noção de que humanos são os únicos responsáveis pelo delineamento das práticas sociais dentro das organizações. Nesse sentido, seria difícil dizer que um gerente estabelece um cronograma de ação sem um computador ou papel e caneta ou, ainda, assegurar que um relatório financeiro possa ser gerado sem dados inseridos num programa por um humano. A natureza isolada (das ações) de objetos e pessoas é, então, revista pela idéia de simetria, o que possibilita ampliar a diversidade de elementos ativos nas práticas organizacionais, colocando em cena entidades antes vistas somente como elementos passivos.

O processo organizativo é o resultado de arranjos e práticas mais ou menos estáveis e temporalmente duráveis, uma vez que a agregação de novos elementos não-humanos é capaz de reordenar ações, até então tidas como certas. A produção de organizações é um processo complexo e heterogêneo, porque além da diversidade de humanos que as compõem, lidamos com uma série de objetos que expressam símbolos, rotinas e práticas nas quais as pessoas estão constantemente envolvidas, podendo alterá-los ou serem por eles alteradas. Arranjos materiais definem objetivos e traçam caminhos das atividades que deverão ser desenvolvidas pelos atores organizacionais.

Destacamos como direcionamento de pesquisas, no âmbito das organizações brasileiras, as questões que envolvem vigilância e controle de funcionários, utilizando objetos e recorrendo a configurações espaciais como forma de assegurar o "correto" desenvolvimento das atividades, e seu reflexo nas práticas de trabalho. Sugerimos também que qualquer organização pode ser tratada como um efeito de redes heterogêneas. 
Tomando como referência as indagações de Bruni (2005) sobre como os não-humanos poderiam ser observados, acreditamos que é preciso começar a pensar em metodologias que permitam apreender a participação de tais elementos nas práticas cotidianas das organizações. A resposta a esse questionamento transcende o escopo deste artigo, mas merece reflexões e futuros desenvolvimentos para posteriores pesquisas de cunho empírico que se proponham a executar esta tarefa. 


\section{Referências}

ADLER, P. S. The evolving object of software development. Organization, v.12, n.3, 2005.

ALCADIPANI, R.; ALMEIDA, A. Por fora, bela viola; por dentro...: análise crítica sobre a gestão do espaço nas organizações através de um estudo de caso sobre a implementação de um escritório aberto no Brasil. Organizações \& Sociedade, v.17, n.19, 2000.

AMANTINO-DE-ANDRADE, J. A insustentável qualidade da produção científica em administração no Brasil: uma história sem fim? Gestão.Org Revista Eletrônica de Gestão Organizacional, v.5, n.1, jan./maio 2007.

BARLEY, S. R.; KUNDA, G. Bringing work back in. Organization Science, v.12, n.1, p.76-95, 2001.

BLOOMFIELD, B. P.; VURDUBAKIS, T. The outer limits: monsters, actor network and the writing of displacement. Organization, v.6, n.4, 1999.

BLOOR, D. Knowledge and social imagery. London: Routledge \& K. Paul, 1976.

BROWN, S. D. Parasite logic. Journal of Organizational Change Management, v.17, n.4, 2004.

; MIDDLETON, D. J. The baby as virtual object: agency and difference in a neonatal intensive care unit. Environment and Planning D: society and space, v.23, p.695-715, 2005.

BRUNI, A. Shadowing software and clinical records: on the ethnography of non-humans and heterogeneous contexts. Organization, v.12, n.3, 2005.

BURRELL, G.; MORGAN, G. Sociological paradigms and organizational analysis. London: Heinemann, 1979.

BUTTON, G. The curious case of the vanishing technology. In: BUTTON, G. (Ed.). Technology in working order: studies of work, interaction and technology. London: Routledge, 1993.

CALLON, M. Some elements of a sociology of translation: demystifications of the scallops and the fishermen of St. Brieuc Bay. In: LAW, J. (Ed.). Power, action and belief: a new sociology of knowledge? London: Routledge \& Kegan Paul, 1986. . Actor-network theory - the market test. In: LAW, J.; HASSARD, J (Ed.). Actor network theory and after. Oxford: Blackwell Publishers, 1999.

; MUNIESA, F. Economic markets as calculative collective devices. Organization Studies, v.26, n.8, 2005.

CARR, A.; DOWNS, A. Transitional and quasi-objects in organization studies: viewing Enron from the object relations world of Winnicott and Serres. Journal of Organizational Change Management, v.17, n.4, 2004.

CASTREE, N. False antitheses? Marxism, nature and actor-networks. Antipode 34, n.1, 2002.

COLLINS, H. M.; YEARLEY, S. Epistemological chicken. In: PICKERING, A. A science as practice and culture. Chicago: University of Chicago Press, 1992. p.396-389.

CONTU, A.; WILLMOTT, H. Studying practice: situating talking about machines. Organization Studies, v.27, n.12, 2006.

COOPER, R; LAW, J. Organization: distal and proximal views. In: BACHARACH, S. B.; GAGLIARDI, P; MUNDELL, B. Research in the sociology of organization. Greenwich, CT: JAI Press, 1995

DREYFUS, H. L. How Heidegger defends the possibility of a correspondence theory of truth with respect to the entities of natural science. In: SCHATZKI, T. R.; KNORR-CETINA, K.; VON SAVIGNY, E. (Ed.). The practice turn in contemporary. London: Routledge, 2001.

EDGE, D. The social shaping of technology. In: HEAP, E. et al. Information technology and society: a reader. London: The Open University/Sage, 1994. 
O objeto objeto na análise organizacional: a teoria atorrede como método de análise da participação dos não-

ENGESTRÖM, Y.; BLACKLER, F. On the life of the object. Organization, v.12, n.3, 2005.

FOOK, J. Theorizing from practice: towards an inclusive approach for social work research. Qualitative Social Work, v.1, n.1, 2002.

FULLER, S. Why science studies has never been critical of science: some recent lessons on how to be a helpful nuisance and a harmless radical. Philosophy of the Social Science, v.30, n.1, 2000.

GANE, N. Post-human. Theory Culture Society, v.23, n.2/3, 2006.

GARFINKEL, H. Studies in ethnomethodology. Cambridge: Polity, 1967.

GHERARDI, S. Practice-based theorizing on learning and knowing in organizations. Organization, v.7, n.2, p.211-223, 2000.

GRINT, K; WOOLGAR, S. The theories of technology. In: The machines at work. Cambridge: Polity Press, 1997.

HAGEMEIJER, R. E. After the fact. Journal of Organizational Change Management, v.17, n.4, 2004.

HANSEN, A.; MOURITSEN, J. Managerial technology and netted networks. competitiveness in action: the work of translating performance in a high-tech firm. Organization, v.6, n.3, 1999.

HARAWAY, D. Simians, cyborgs and women: the reinvention of nature. London: Free Association Books, 1991.

HASSARD, J.; LAW, J.; LEE, N. Preface. Organization, v.6, n.3, 1999.

HULL, R. Actor network and conduct: the discipline and practices of knowledge management. Organization, v.6, n.3, 1999.

JAPIASSÚ, H.; MARCONDES, D. Dicionário básico de filosofia. Rio de Janeiro: Jorge Zahar Ed., 1996.

JARZABKOWSKI, P. Strategy as practice: recursiveness, adaptation and practices-in-use. Organization Studies, v.25, n.4, p.529-560, 2004.

Strategy as practice: an activity-based approach. London: Sage Publications, 2005.

KIRSCH, S.; MITCHELL, D. The nature of things: dead labor, nonhuman actors, and the persistence of Marxism. Antipode, v.36, n.4, p.687-705, 2004.

KNORR-CETINA, K. Citation for David Bloor. Science, Technology \& Human Values, v.22, n.3, 1997 a.

. Sociality with objects: social relation in post-social knowledge societies. Theory, Culture \& Society, v.14, n.4, 1997b.

Objectual practice. In: SCHATZKI, T. R.; KNORR-CETINA, K.; VON SAVIGNY, E. (Ed.). The practice turn in contemporary. London: Routledge, 2001.

KUHN, T. Book review. Organization, v.12, n.3, 2005.

LATOUR, B. Jamais fomos modernos: ensaios de antropologia simétrica. Rio de Janeiro: Editora 34, 1994a.

. Pragmatogonies. American Behavioral Scientist, v.37, n.6, 1994b.

. On recalling ANT. In: LAW, J; HASSARD, J (Ed.). Actor network theory and after. Oxford: Blackwell Publishers, 1999.

. Ciência em ação: como seguir cientistas e engenheiros sociedade afora. São Paulo: Editora Unesp, 2000.

. A esperança de pandora: ensaios sobre a realidade dos estudos científicos. São Paulo: Edusc, 2001.

. Is Re-modernization occurring - and if so, how to prove it? Theory, Culture \& Society, v.20, n.2, 2003. 
O objeto objeto na análise organizacional: a teoria atorrede como método de análise da participação dos não-

Reassembling the social: an introduction to actor-network theory. New York: Oxford University Press, 2005.

; WOOLGAR, S. A vida de laboratório: a produção dos fatos científicos. Rio de Janeiro: Relume Dumará, 1997.

LAW, J. On the methods of long distance control: vessels, navigation and the Portuguese rout to India. In: LAW, J (Ed.). Power action and belief: a new sociology of knowledge? London: Routledge \& Kegan Paul, 1986. (Sociological Review Monograph 32).

. Notes on the theory of the actor network: ordering, strategy and heterogeneity. 1992. Recuperado em 22 de novembro de 2005 do Centre for Science Studies, Lancaster University, Lancaster LA1 4YN. Disponível em: $<$ http://www.comp.lancs.ac.uk/sociology/papers/Law-Notes-on-ANT.pdf>.

Organizing modernity. Oxford, UK: Blackwell, 1994.

Topology and the naming of complexity. 1997a. Recuperado em 22 de novembro de 2005 do Centre for

Science Studies, Lancaster University, Lancaster LA1 4YN, UK. Disponível em: $<$ http://www.comp.lancs.ac.uk/sociology/papers/Law-Topology-and-Complexity.pdf >.

Heterogeneities. 1997b. Recuperado em 22 de novembro de 2005 do Centre for Science Studies, Lancaster University, Lancaster LA1 4YN, UK. Disponível em: <http://www.comp.lancs.ac.uk/sociology/papers/LawHeterogeneities.pdf>.

The manager and his powers. 1997c. Recuperado em 22 de novembro de 2005 do Centre for Science Studies, Lancaster University, Lancaster LA1 4YN, UK. Disponível em: <http://www.comp.lancs.ac.uk/sociology/papers/LawManager-and-his-Powers.pdf>.

After ANT: complexity, naming and topology. In: ; HASSARD, J. (Ed.). Actor-network theory and after. Oxford: Blackwell Publishers, 1999a.

Traduction/trahison: notes on ANT. 1999b. Recuperado em 22 de novembro de 2005 do Centre for Science Studies, Lancaster University, Lancaster LA1 4YN, UK. Disponível em: <http://www.comp.lancs.ac.uk/sociology/papers/lawtraduction-trahison.pdf>.

Disasters, a/symmetries and interferences. 2003. Recuperado em 22 de novembro, 2005 do Centre for Science Studies, Lancaster University, Lancaster LA1 4YN, UK. Disponível em: $<$ http://www.comp.lancs.ac.uk/sociology/papers/law-disasters-asymmetries-and-interferences>.

. After method: mess in social science research. London: Routledge, 2004.

; MOSER, I. Managing, subjectivities and desires. 1999. Recuperado em 22 de novembro de 2005 do Centre for Science Studies, Lancaster University, Lancaster LA1 4YN, UK. Disponível em: $<\underline{\text { http://www.comp.lancs.ac.uk/sociology/soc019jl.html }>\text {. }}$

; SINGLETON, V. Object lessons. Organization, v.12, n.3, 2005.

; URRY, J. Enacting the social. Economy and Society, v.33, n.3, p.390-410, 2004.

LEE, N.; HASSARD, J. Organization unbound: actor-network theory, research strategy and institutional flexibility. Organization, v.6, n.3, 1999.

LETICHE, H.; HAGEMEIJER, R. E. Linkages and entrainment. Journal of Organizational Change Management, v.17, n.4, 2004.

LOWE, A. Objects and the production of technological forms of life: understanding organisational arrangements from a post-social perspective. Journal of Organizational Change Management, v.17, n.4, 2004. 
MACKENZIE, D.; WACJMAN, J. Introduction. In: . The social shaping of technology. Philadelphia: Open University Press, 1999.

McLEAN, C; QUATTRONE, P. On theorizing the object: insights from Gabriel Tarde. Gabriel Tarde: Economy, Psychology and Invention Conference, May 2006, London.

MEHAN, H.; WOOD, H. An image of man for ethnomethodology. Philosophy of the Social Sciences, v.5, n.3, 1975.

MIETTINEN, R.; VIRKKUNEN, J. Epistemic objects, artefacts and organizational change. Organization, v.12, n.3, 2005.

MISOCZKY, M. C. A.; AMANTINO-DE-ANDRADE, J. A. Quem tem medo do fazer acadêmico enquanto práxis. Revista de Administração Contemporânea - RAC, v.9, n.1, 2005.

MOL, A. The body multiple: artherosclerosis in practice. Durham: Duke University Press, 2002.

MOSER, I.; LAW, J. Good passages, bad passages. In: LAW, J; HASSARD, J (Ed.). Actor-network theory and after. Oxford: Blackwell Publishers, 1999.

MUNRO, R. Power and discretion: membership work in the time of technology. Organization, v.6, n.3, 1999.

ORLIKOWSKI, W. J. Knowing in practice: enacting a collective capability in distributed organizing. Organization Science, v.13, n.3, p.249-273, 2002.

ORR, J. E. Talking about machines: an ethnography of a modern job. Ithaca, NY: ILR Press, 1996.

PAÇO-CUNHA, E. et al. Práticas versus táticas: praxeologia do poder numa organização de tecnologia. In: ENCONTRO DA ASSOCIAÇÃO NACIONAL DOS PROGRAMAS DE PÓS-GRADUAÇÃO EM ADMINISTRAÇÃO, 2006, Salvador. Anais... Bahia: Anpad. 1 CD ROM.

PARKER, M. Judgement day: cyborganization, humanism and postmodern ethics. Organization, v.5, n.4, 1998.

PICKERING, A. Practice and post-humanism: social theory and a history of agency. In: SCHATZKI, T. R.; KNORR-CETINA, K.; VON SAVIGNY, E. (Ed.). The practice turn in contemporary. London: Routledge, 2001.

PINCH, T.; BIJKER, W. E. The social construction of facts and artefacts: or how the sociology of science and the sociology of technology might benefit each other. Social Studies of Sciences. v.14, 1984.

The social constructions of facts and artefacts: or how the sociology of science and the sociology of technology might benefit each other. In: BIJKER, W. E.; HUGHES, T. P.; PINCH, T. (Ed.). The social construction of technological systems: new directions in the sociology and history of technology. Cambridge, MA: The MIT Press, 1987.

RASCHE, A.; CHIA, R. Strategy practices - what they are (not). In: EUROPEAN GROUP OF ORGANIZATION STUDIES, 23. , 2007, Vienna.

RECKWITZ, A. Toward a theory of social practices: a development in culturalist theorizing. European Journal of Social Theory, v.5, n.2, 2002.

SCHATZKI, T. R. Social practice: a Wittgenstein approach to human activity and the social. Cambridge: Cambridge University Press, 1996.

. Introduction: practice theory. In: ; KNORR-CETINA, K; VON SAVIGNY, E. (Ed.). The practice turn in contemporary. London: Routledge, 2001a.

Practice mind-ed orders. In: ; KNORR-CETINA, K; VON SAVIGNY, E (Ed.). The practice turn in contemporary. London: Routledge, 2001b.

The site of the social: a philosophical account of the constitution of social life and change. Pennsylvania: Pennsylvania State University Press, 2002. 
O objeto objeto na análise organizacional: a teoria atorrede como método de análise da participação dos não-

. A new societist social ontology. Philosophy of the Social Sciences, v.33, n.2, 2003.

The sites of organizations. Organization Studies, v.26, n.3, 2005.

. On organizations as they happen. Organization Studies, v.27, n.12, p.1863-1873, 2006.

; KNORR-CETINA, K; VON SAVIGNY, E. (Ed.). The practice turn in contemporary. London: Routledge, 2001.

SCHINKEL, W. "Inertia creeps", or a phenomenological perspective on objects in sociology. Journal of Organizational Change Management, v.17, n.4, 2004.

SUCHMAN, L. Affiliative objects. Organization, v.12, n.3, 2005.

et al. Reconstructing technologies as social practice. American Behavioral Scientists, v.43, n.3, 1999.

VANDENBERGHE, F. Reconstructing humants: a humanist critique of actant-network theory. Theory, Culture \& Society, v.19, n.5/6, p.51-67, 2002.

WARDE, A. Consumption, identity-formation and uncertainty. Sociology - the Journal of the British Sociological Association, v.28, n.4, p.877-898, 1994.

WHITTINGTON, R. Strategy as practice. Long Range Planning, v.29, n.5, 1996.

WILLIAMS, R.; EDGE, D. The social shaping of technology. In: DUTTON, W. Information and communication technologies: visions and realities. [S.I.]: Oxford Press, 1996.

YANOW, D. Talking about practices: on Julian Orr's talking about machines. Organization Studies, v.27, n.12, p.1743$1756,2006$. 


\section{Notas}

${ }^{1}$ Palitinhos de madeira usados como talheres pelos japoneses.

${ }^{2}$ Para uma revisão das influências epistemológicas das diversas teorias das práticas veja: Schatzki, Knorr Cetina e Von Savigny (2001) e Rasche e Chia (2007).

${ }^{3}$ Entendemos por teoria social moderna o grupo de teorias afiliadas aos paradigmas do homo economicus e do homo sociologicus, e que são ancoradas em fortes conceitos sobre a racionalidade das ações humanas e da ordem social (RECKWITZ, 2002).

${ }^{4}$ Ações e falas significam ações que as pessoas realizam corporalmente - como, por exemplo, correr, compor poemas, olhar, pagar aos fornecedores ou construir uma casa (SCHATZKI, 2001b) -, e somente dizem respeito a uma determinada prática se expressarem componentes inerentes à sua organização (SCHATZKI, 2002).

${ }^{5}$ Os objetos podem ser entendidos como elementos materiais tal como os conhecemos pelo senso comum; ou seja, caneta, computador, celular etc. Elementos não-humanos referem-se a um conceito mais abrangente e incluem, além dos objetos, materiais como software de computador ou um artefato organizacional.

${ }^{6}$ Talvez, o marco da popularização da TAR nos estudos organizacionais tenha sido o ano de 1999, quando John Hassard, John Law e Nick Lee coordenaram uma edição especial sobre essa abordagem na revista Organization, na qual foram publicados quatro artigos que tratavam do tema (ver HANSEN; MOURITSEN, 1999; HULL, 1999; LEE; HASSARD, 1999; MUNRO, 1999; e ver também prefácio de HASSARD; LAW;LEE, 1999). A edição especial foi o resultado da conferência "Actor-network theory and after", realizada na Universidade de Keele, em setembro de 1997, e que contou com uma grande audiência; maior, inclusive, do que os organizadores esperavam.

${ }^{7}$ Os termos humano e não-humano não representam a superação da dicotomia sujeito/objeto, mas sim um meio de ultrapassá-la completamente (LATOUR, 2001).

${ }^{8}$ Para exemplos de como humanos e não-humanos são capazes de agir ao se associarem, ver Law (1999b).

${ }^{9}$ Latour (2001) observa que, dado o significado da palavra "actor" (ator) em inglês se limitar a humanos, na TAR o termo "actant' (atuante), emprestado da semiótica, é utilizado para incluir não-humanos na definição.

${ }^{10}$ Esse termo diz respeito às associações estabelecidas entre humanos e não-humanos (LATOUR, 2001). 